\title{
Characterization of the locus encoding the [Ni-Fe] sulfhydrogenase from the archaeon Pyrococcus furiosus: evidence for a relationship to bacterial sulfite reductases
}

\author{
Paola Pedroni, Anna Della Volpe, Giuliano Galli, Giovanni M. Mura, \\ Claudio Pratesi and Guido Grandi
}

Author for correspondence: Guido Grandi. Tel: +39 25205970. Fax: +39 252022974.

ENIRICERCHE S.p.A. Genetic Engineering and Microbiology Laboratories, Via F. Maritano, 26 San Donato Milanese 20097 Milan, Italy
The hydBGDA genes, which encode the four subunits $\beta, \gamma, \delta$ and $\alpha$ of the [Ni-Fe] hydrogenase from the archaeon Pyrococcus furiosus, have been isolated and sequenced using a PCR/IPCR-based strategy. From the sequence analysis it appears that the four structural genes are tightly linked and organized in a single transcription unit. The hydD and hydA gene products are related to the small and the large subunits of several archaeal and eubacterial [Ni-Fe] hydrogenases with an overall degree of sequence relatedness ranging from $35 \%$ to $50 \%$ (identity + similarity). In particular, the amino acid sequence motifs involved in the accommodation of nickel and iron-sulfur clusters are conserved. In addition, the database search revealed that the hydB and hydG gene products are homologous to the asrA- and asrB-encoded subunits of the sulfite reductase enzyme from Salmonella typhimurium. This is particularly interesting in view of the recent finding that the $P$. furiosus hydrogenase appears to be a bifunctional enzyme endowed with both proton- and sulfurreducing activities.

Keywords: hydrogenase, Pyrococcus furiosus, archaea, sulfur reduction, sulfite reductase

\section{INTRODUCTION}

Recently, largely through the efforts of Stetter and coworkers, a number of bacterial species able to grow well above $80^{\circ} \mathrm{C}$ and belonging to the archaea have been isolated from several geothermic terrestrial and marine environments (Stetter, 1986).

Among these species the 'hyperthermophiles' grow optimally around $100{ }^{\circ} \mathrm{C}$, are strict anaerobes, and most of them depend on the reduction of elemental sulfur $\left(\mathrm{S}^{0}\right)$ for growth. Pyrodictium brockii (Stetter et al., 1983) and Pyrobaculum islandicum (Huber et al., 1987) obtain energy for growth by $\mathrm{S}^{0}$ respiration, the former being an obligate autotroph which reduces $\mathrm{S}^{0}$ to $\mathrm{H}_{2} \mathrm{~S}$ with $\mathrm{H}_{2}$ whereas the latter, a facultative heterotroph, reduces $\mathrm{S}^{0}$ with either $\mathrm{H}_{2}$ or organic substrates. On the other hand, Pyrococcus furiosus (Fiala \& Stetter, 1986) can grow in the absence of

\footnotetext{
Abbreviation: IPCR, inverse polymerase chain reaction.
}

The GenBank/EMBLDDBJ accession number for the nucleotide sequence data reported in this paper is $X 75255$.
$\mathrm{S}^{0}$, fermenting simple and complex carbohydrates and producing $\mathrm{H}_{2}$ and $\mathrm{CO}_{2}$ as detectable products. In the presence of $\mathrm{S}^{0}, \mathrm{H}_{2} \mathrm{~S}$ is produced and the biomass yield is increased. The reduction of $\mathrm{S}^{0}$ was postulated to take place to prevent the growth inhibitory effect of the $\mathrm{H}_{2}$ produced during fermentation (Bryant \& Adams, 1989). However, a recent study performed with an energylimited continuous culture system has shown that in $P$. furiosus the reduction of $\mathrm{S}^{0}$ is an energy-conserving reaction which directly or indirectly participates in the energy balance by an unknown mechanism (Schicho et al., 1993).

In studying the sulfur metabolism of $P$. furiosus, $\mathrm{Ma}$ and coworkers found that elemental sulfur reduction is carried out by a sulfur reductase present in the cytoplasm (Ma et al., 1993). Interestingly, the same authors showed that the sulfur reductase activity is associated with the previously characterized soluble hydrogenase, suggesting that the cytoplasmic production of $\mathrm{S}^{2-}$ might be coupled to the $\mathrm{H}^{+}$ reduction by a bifunctional enzyme, a sulfhydrogenase.

$P$. furiosus hydrogenase, first isolated by Bryant \& Adams (1989), is remarkably resistant to inactivation by tem- 
perature and chemical agents. The enzyme remains $50 \%$ active after $21 \mathrm{~h}$ incubation at $80^{\circ} \mathrm{C}$ and is not affected by the presence of SDS $(0.1 \%)$ and $\beta$-mercaptoethanol $(2 \%$, $\mathrm{w} / \mathrm{v})$. Further characterization has shown that the $150 \mathrm{kDa}$ enzyme is organized in an $\alpha \beta \gamma \delta$ tetrameric structure (Mura et al., 1991).

To understand better the structural characteristics of the $P$. furiosus hydrogenase and its bifunctional properties associated with proton and sulfur reduction, we have isolated and characterized the DNA encoding this enzyme. In this communication we give the complete nucleotide sequence of the hydrogenase gene cluster. We have found that while two of the four subunits $(\alpha$ and $\delta$ ) are homologous to the large and the small subunits of dimeric and multimeric $[\mathrm{Ni}-\mathrm{Fe}]$ hydrogenases, the $\beta$ and $\gamma$ subunits share extensive homologies with the products of the sulfite reductase genes (asr $A$ and asr $B$ ) from Salmonella typhimurium (Huang \& Barrett, 1991). These findings and the genetic relationship of the $P$. furiosus byd genes to the other $[\mathrm{Ni}-\mathrm{Fe}]$ hydrogenases are discussed in light of the biochemical properties of the $P$. furiosus enzyme.

\section{METHODS}

Chemicals. Restriction and modification enzymes, purchased from Boehringer Mannheim or Promega, were used as recommended by the manufacturers. Reagents for DNA sequencing were supplied by US Biochemical and New England Biolabs. For the PCR and IPCR amplifications both Taq DNA polymerase (Boehringer Mannheim) and cloned P. furiosus DNA polymerase (Stratagene) were used.

Bacterial strains and growth conditions. P. furiosus (DSM 3638) was grown at $85^{\circ} \mathrm{C}$ in closed static cultures using a synthetic seawater-based medium (SME) (Stetter et al., 1983) supplemented with tryptone $\left(5 \mathrm{~g} \mathrm{l}^{-1}\right)$, yeast extract $\left(1 \mathrm{~g} \mathrm{l}^{-1}\right)$, Lcysteine $\left(0.5 \mathrm{~g} \mathrm{l}^{-1}\right)$ and $1 \mathrm{ml} 0.2 \%$ resazurin solution as redox indicator. The $\mathrm{pH}$ was adjusted to 6.2 with $\mathrm{HCl}$ and anaerobic conditions were obtained by flushing the medium with argon for $30 \mathrm{~min}$.

For large-scale growth, $15 \mathrm{l}$ fermenters (Setric GI) were inoculated with $500 \mathrm{ml}$ cultures grown in sealed bottles for $24 \mathrm{~h}$. Fermentations were carried out at $95^{\circ} \mathrm{C}$ with agitation (300 r.p.m.) in an argon atmosphere $\left(300 \mathrm{ml} \mathrm{min} \mathrm{m}^{-1}\right)$. Growth was monitored by following the increase in turbidity at $660 \mathrm{~nm}$ and $\mathrm{H}_{2}$ production was analysed using a Varian 3400 gas chromatograph. Cells were harvested after $24 \mathrm{~h}$ (final $\left.\mathrm{OD}_{660}=0.25\right)$, washed in $50 \mathrm{mM}$ Tris $/ \mathrm{HCl}(\mathrm{pH} 8)$ and stored at $-80^{\circ} \mathrm{C}$. The biomass yield (dry weight) was $270 \mathrm{mg} \mathrm{l}^{-1}$.

Escherichia coli strain TG1 [supE bsd $\Delta 5$ thi $\Delta($ lac-pro $A B)$ $\mathrm{F}^{\prime}$ (traD36 pro $A B^{+}$lac $\mathrm{T}^{\mathrm{a}}$ lac $\left.\left.Z \Delta M 15\right)\right]$ was grown aerobically at $37^{\circ} \mathrm{C}$ in Luria-Bertani (LB) medium. Competent E. coli TG1 cells were prepared and electroporated following the method previously described (Dower et al., 1988). Recombinants were screened on LB agar plates containing ampicillin $\left(100 \mu \mathrm{g} \mathrm{ml}^{-1}\right)$, 5-bromo-4-chloro-3-indolyl- $\beta$-D-galactopyranoside (X-Gal) $\left(40 \mu \mathrm{g} \mathrm{ml}^{-1}\right)$ and isopropyl $\beta$-D-thiogalactopyranoside (IPTG) $\left(125 \mu \mathrm{g} \mathrm{ml}^{-1}\right)$.

Purification of $\boldsymbol{P}$. furiosus hydrogenase. P. furiosus hydrogenase was partially purified as described by Bryant \& Adams (1989). Sequencing grade enzyme preparations were obtained by gel elution. In particular, the partially purified enzyme was run on a $10 \%(\mathrm{w} / \mathrm{v})$ SDS-polyacrylamide gel and stained to visualize the hydrogenase activity (see below). The activity band was excised from the gel and electroeluted with a 422 Electroeluter (Bio-Rad) in Tris/glycine/ $0.1 \%$ SDS buffer (LeGendre \& Matsudaira, 1989). The individual subunits of $P$. furiosus hydrogenase were completely dissociated by boiling the electroeluted enzyme $\left(10 \mathrm{~min}\right.$ at $\left.100^{\circ} \mathrm{C}\right)$ and by running it on a $10 \%$ SDS-polyacrylamide gel. Following the electrophoretic separation, the protein was transferred to a polyvinylidene difluoride (PVDF) membrane (Millipore) as described elsewhere (Matsudaira, 1987). The N-terminal sequence of each subunit was determined by Edman degradation using a Beckman sequenator.

Proteins were determined spectrophotometrically with the BioRad micromethod based on the Bradford assay (Bradford, 1976) using bovine serum albumin as the standard. SDS-PAGE was performed according to Laemmli (1970).

Hydrogenase activity. Hydrogenase activity was routinely determined by following $\mathrm{H}_{2}$ evolution at $80^{\circ} \mathrm{C}$ as described previously (Adams \& Mortenson, 1984) using a Varian 3400 Gas Chromatograph equipped with a $5 \AA$ molecular sieve column ( $1 \mathrm{~m}, 1 / 8 \mathrm{inch})$. One unit of hydrogenase activity is defined as the amount of enzyme which catalyses the production of $1 \mu \mathrm{mol} \mathrm{H}_{2} \min ^{-1}$.

Colorimetric visualization of hydrogenase activity on $10 \%$ SDS-polyacrylamide gels was performed at $70{ }^{\circ} \mathrm{C}$ as already described (Bryant \& Adams, 1989).

Recombinant DNA techniques. The molecular biology methods were according to standard protocols (Sambrook $e t$ al., 1989). When necessary, the subcloning of the PCR and IPCR (Ochman et al., 1990) fragments was done using the pUC18 plasmid from Boehringer Mannheim or the pCRII TA cloning kit from Invitrogen.

Oligonucleotide synthesis. Oligodeoxynucleotides used for sequencing and amplifications were synthesized with Beckman DNA Synthesizers (models SM and OLIGO 1000). When required, the oligodeoxynucleotides were purified according to the specifications provided by Beckman. The following primers were used (from $5^{\prime}$ to $3^{\prime}$; deg $=$ degenerate): $\alpha 1 \mathrm{deg}$, ATGAA(AG)AA(TC)CT(TC)TA(TC)CT(TC)CC; $\alpha 2 \mathrm{deg}, \mathrm{T}^{\prime} \mathrm{TTCC}(\mathrm{TC})$ TC(AT)AC(TC)CT(AT)GC(AT)AT; $\beta 1 \mathrm{deg}, \mathrm{GA}($ AG)AA(TC)AC(TA)TA(TC)GA(AG)T'T(TC)CT(TC)GA; $\beta 2$ deg, TT(AT)AC(TA)GG(AT)GC(AG)TA(GA)AG(TC)TTTCC; $\delta 1 \mathrm{deg}$, GGAAA(AG)GT(TA)AG(AG)AT(TA)GGATT(TC)TA; $\delta 2 \mathrm{deg}, \mathrm{AC}(\mathrm{AT}) \mathrm{AT}(\mathrm{TC}) \mathrm{TC}(\mathrm{AT}) \mathrm{GC}(\mathrm{AG}) \mathrm{TT}(\mathrm{TA}) \mathrm{TG}(\mathrm{AT}) \mathrm{AT}$; p1, GATAAGTTGTAATAACTCGTCCATCATAGCTAG; p2, CCAATCACCATTGATCATAT; p3, GAAAGACTTAAAGACTGGGG; p4, GCGATAACCGTAGTTGATGAG; p5, GTCAGCTGAACAAACTGTCCAG; p6, GCAGATAAGTGCTTGGCTTGTGG; p7, ATGGTTCAACTTCCTCTATTAC.

Isolation of hydrogenase genes. The forward and reverse primers were used to amplify either linear (PCR) or restrictionenzyme-digested and self-ligated (IPCR) $P$. furiosus chromosomal DNA. PCR and IPCR reactions ( 30 cycles of denaturation at $94{ }^{\circ} \mathrm{C}$ for $1 \mathrm{~min}$, annealing at the appropriate temperature for $1 \mathrm{~min}$ and elongation at $72^{\circ} \mathrm{C}$ for $2 \mathrm{~min}$ ) were performed in $100 \mu \mathrm{l}$ mixtures covered with $100 \mu \mathrm{l}$ mineral oil. Reaction samples included: template genomic DNA (500 ng undigested DNA in the case of PCR, $20 \mathrm{ng}$ restriction-enzyme-digested and self-ligated DNA in the case of IPCR), $200 \mu \mathrm{M}$ dNTPs, 150 pmol degenerate primers or 100 pmol specific primers and $2.5 \mathrm{U}$ of either Taq DNA polymerase or $P$. furiosus DNA 
(a)

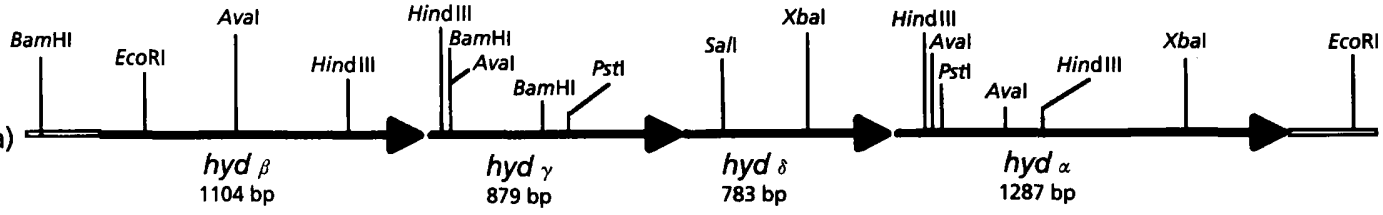

(b)

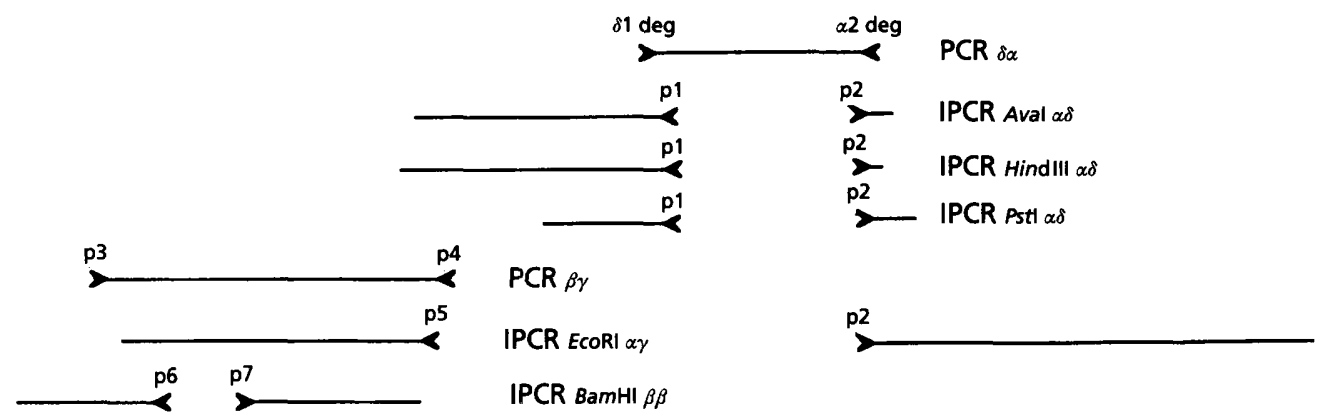

Fig. 1. (a) Restriction map and physical organization of the $4180 \mathrm{bp}$ fragment carrying the $P$. furiosus hydBGDA genes encoding the $\beta, \gamma, \delta$ and $\alpha$ hydrogenase subunits. The thick arrows indicate the coding regions and the orientation of the four genes. (b) Schematic representation of the PCR and IPCR fragments used to isolate the entire hydrogenase gene cluster. Arrowed lines indicate the amplification directions.

polymerase. The amplification reactions were carried out using a Perkin Elmer Cetus thermal cycler.

Nucleotide sequencing and analysis. DNA sequencing was performed on both strands by the dideoxy chain-termination method (Sanger et al., 1977) using the Sequenase version 2.0 (US Biochemical) and the CircumVent (New England Biolabs) sequencing kits. Routinely, different plasmids carrying the same IPCR fragment and different IPCR fragments covering the same DNA region were sequenced to avoid sequencing errors due to the non-perfect fidelity of polymerases.

The strategy used for the isolation and sequencing of the hydrogenase cluster is given in Fig. 1. Initially, using the $\delta 1 \mathrm{deg} / \alpha 2 \mathrm{deg}$ primer combination a fragment of about $700 \mathrm{bp}$ was obtained. This suggested that the $\alpha$ subunit is linked to and preceded by the $\delta$ subunit coding sequence in the hydrogenase cluster. The $700 \mathrm{bp}$ fragment containing the $\delta$ subunit gene and the $5^{\prime}$ region of the $\alpha$ subunit was sequenced. Subsequently, the genomic DNA was digested with different restriction enzymes, self-ligated and amplified with two divergently oriented oligonucleotides $(\mathrm{p} 1 / \mathrm{p} 2)$ annealing to the $5^{\prime}$ ends of the $\delta$ subunit gene and the $\alpha$ subunit gene, respectively. The analysis of these IPCR products allowed us to complete most of the sequence of the $\gamma$ subunit and to extend further the sequence of the $\alpha$ subunit. The remaining part of the $\gamma$ subunit and most of the $\beta$ subunit were isolated by PCR performed with the convergently oriented primers $\mathrm{p} 3$ and $\mathrm{p} 4$ corresponding to the $5^{\prime}$ ends of the $\beta$ and $\gamma$ subunits, respectively. The entire $\beta$ subunit and the putative promoter region were obtained by amplifying the BamHI-cut, self-ligated chromosomal DNA with two divergently oriented primers ( $6 / \mathrm{p}^{7}$ ) annealing to the internal part of the $\beta$ subunit. Finally, the entire $\alpha$ subunit was amplified from the EcoRI-cut, self-ligated genomic DNA using a combination of primers (p5/p2) corresponding to the $5^{\prime}$ ends of the $\alpha$ and $\gamma$ subunit genes, respectively.

The sequence was compiled and analysed by using the PC/GENE software package (IntelliGenetics). Multiple amino acid sequence alignments were performed using the MACAW program (Schuler et al., 1991).

\section{RESULTS AND DISCUSSION}

\section{Isolation and sequencing of the $P$. furiosus hydrogenase (hyd) genes}

The four hydrogenase subunits having molecular masses of $50000,43000,33000$ and $31000 \mathrm{Da}$ were purified from a SDS-polyacrylamide gel as described in Methods and Nterminal sequenced. Degenerate forward and reverse primers were designed on the basis of the $\mathrm{N}$-terminal sequences of the $\alpha, \beta$ and $\delta$ subunits and were used in initial PCR amplifications of the $P$. furiosus genomic DNA. The degeneracy of the oligonucleotides was lowered by taking into account the codon usage in the glyceraldehyde-3-phosphate dehydrogenase gene of the phylogenetically related organism Pyrococcus wosei (Zwickl et al., 1990). The amplification of the $5^{\prime}$ end of the $\gamma$ subunit DNA was not attempted because of the limited length of the amino acid sequence available. The DNA sequences of the $\alpha, \beta$ and $\delta$ PCR products were in perfect agreement with the $\mathrm{N}$-terminal sequences of the three subunits.

The knowledge of the sequences of the $5^{\prime}$ ends of the byd $A$, byd $B$ and bydD genes allowed us to determine the nucleotide sequence of the entire region containing the four genes using a strategy, described in Methods, based on the analysis of different PCR and IPCR products. The restriction map and the physical organization of the 4180 bp fragment carrying the $P$. furiosus byd genes is shown in Fig. 1.

\section{Sequence analysis}

The nucleotide sequence and the derived amino acid sequences of the DNA region comprising the $P$. furiosus byd genes are shown in Fig. 2. 
AAACAAAAATGTTCACTAACGAAAATTTGAGGAGTATTGGTCAATTATGCTCATTGGGAG GTGGTITGTGTGAGGTATGTTAAGTTACCCAAGGAAAACACTTACGAGTTTTTGGAAAGA

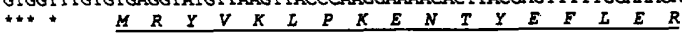
CTTAAAGACTGGGGGAAGCTTTACGCTCCAGTAAAAATTTCGGACAAGTTCTATGACTTC $\begin{array}{rllllllllllllllllllll}L & K & D & W & G & K & L & Y & A & F & V & K & I & S & D & K & F & Y & D & F\end{array}$ AGGGAGATTGATGATGTTAGAAAGATAGAATTCCACTACAACAGGACAATAATGCCACCT $\begin{array}{lllllllllllllllllllll}R & E & I & D & D & V & R & K & I & E & F & H & Y & N & R & T & I & M & P & P\end{array}$ AAGAAGTTCTTCTTCAAGCCGAGGGAAAAGCTCTTTGAGTTCGACATTTCAAAACCAGAA

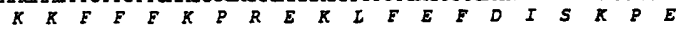
TACAGGGAGGIATAGAGGAAGTTGAACCATTTATTATATTTGGAGTCCACGCGTGTGAC $\begin{array}{lllllllllllllllllll}Y & R & E & V & I & E & E & V & E & P & F & I & I & F & G & V & A & C & D\end{array}$

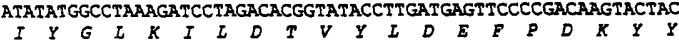
AAGGTGAGGAGAGAGAAGGGGATAATCATTGGAATAGCTGTATGCCACATGAATATTGC $\begin{array}{lllllllllllllllllllll}K & V & R & R & E & K & G & I & I & I & G & I & S & C & M & P & D & E & Y & C\end{array}$ TTCTGTAACTTAAGAGAAACAGACTTCGCTGATGATGGTTTTGACTTGTTCTTCCATGAA $\begin{array}{llllllllllllllllllllll}F & C & N & L & R & E & T & D & F & A & D & D & G & F & D & L & F & F & H & E\end{array}$

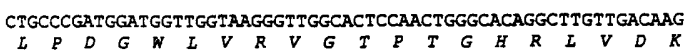

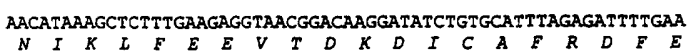
AAGAGGAGACAGCAAGCATTCCAATACCACGAAGACTGGGGCAACTTGAGGTATCTTCTC $\begin{array}{lllllllllllllllllllll}K & R & R & Q & Q & A & F & Q & Y & H & E & D & W & G & N & L & R & Y & L & L\end{array}$ GAGTTGGAAATGGACATCCAATGTGGGATGAGGAGGCAGATAAGTGCTTGGCTTGTGGA $\begin{array}{lllllllllllllllllllll}E & L & E & M & E & H & P & M & W & D & E & E & A & D & K & C & L & A & C & G\end{array}$

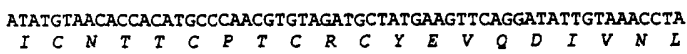
GATGGAGTTACTGGATACAGGGAAAGAAGATGGGATTCTTGTCAGTTCAGAAGTCATGGC $\begin{array}{clllllllllllllllllll}D & G & T & G & Y & R & E & R & R & N & D & S & C & Q & F & R & S & H & G\end{array}$ TTAGTTGCTGGGGGCCACAACTTCAGGCCCACAAAGAAGGATCGCTTTAGGAACAGATAC $\begin{array}{lllllllllllllllllllll}L & V & A & G & G & H & N & F & R & P & T & K & K & D & R & F & R & N & R & Y\end{array}$ CTCTGTAAGAACGCATATAACGAAAAGCTTGGATTAAGCTACTGTGTCGGTTGTGGAAGG $\begin{array}{lllllllllllllllllllll}L & C & K & N & A & Y & N & E & K & L & G & L & S & Y & C & V & G & C & G & R\end{array}$ TGTACTGCATTCTGTCCAGCCAATATAAGTTTTGTAGGCAATCTTAGAAGGATTTTAGGA $\begin{array}{llllllllllllllllllllll}C & I & A & F & C & P & A & N & I & S & F & V & G & N & L & R & R & I & L & G\end{array}$ CTTGAGGAGAACAAATGTCCCCCAACGGTTAGTGAGGAGATTCCAAAGAGAGGATTTGCA $\begin{array}{llllllllllllllllllll}I & E & E & N & K & C & F & P & T & V & S & E & E & I & P & K & R & G & F & A\end{array}$ AITCCTCTAACATTAGAGGTGATGGAGTATGATGTTGCCAAAAGAGATTATGATGCCAA $Y S S N I R G$ S G V

$M \quad L E R E I M M E$ ATGATAATCCGTATGCCCTTCATAGAGTCAAAGTTCTAAAGGTTTACTCCTTGACGGAAA $\begin{array}{llllllllllllllllllll}N & D & N & P & Y & A & L & H & R & V & K & V & L & K & V & Y & S & L & T & E\end{array}$ CGGAAAGCTTTTCCTCTTTAGATTTGAGGATCCCGAGTTGGCAGAGAGTGGACGTTCA $\begin{array}{llllllllllllllllllll}T & E & K & L & F & L & F & R & F & E & D & P & E & I & A & E & K & N & T & E\end{array}$

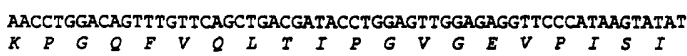
GCTCTICTCCAATGAGGAAAGGATTCTITGAGCTCTGTATAAGAARGGCAGGAAGGGTCA $\begin{array}{llllllllllllllllllll}C & S & S & F & A & K & G & F & E & E & L & C & I & R & K & A & G & R & V\end{array}$ CAACTGTTGTCCATAGACTAAAGCCTGGCGATACTGTTCTTGTGAGAGGGCCTIACGGTA $\begin{array}{lllllllllllllllllllll}T & T & V & V & H & R & L & K & P & G & D & T & V & L & V & R & G & P & Y & G\end{array}$ ATGGATTCCCAGTGGATGAGTGGGAGGAATGGATCTACTATTAATAGCTGCTGGCCTTG $\begin{array}{lllllllllllllllllllll}N & G & E & P & V & D & E & W & E & G & M & D & E & L & L & I & A & A & G & L\end{array}$ GAACTGCACCTCTTAGGAGCGTCTTTCTCTATGCAATGGACAACAGGTGGAGTATGGAA $\begin{array}{lllllllllllllllllllllll}G & T & A & P & L & R & S & V & F & L & Y & A & M & V & N & R & W & K & Y & G\end{array}$ ACATTACCTTCATAAACACCGCACGTTATGGGAAGGATCTCCTCTTCTACAAGGAGCTGG AGGCAATGAAAGACCTAGCTGAGGCTGAAAACGTGAAAATCATCCAGAGCGTCACTAGGG $\begin{array}{llllllllllllllllllll}E & A & M & K & D & L & A & E & A & E & N & V & K & I & I & Q & S & V & T & R\end{array}$ ATCCAAACTGGCCGGGCCTAAAGGTAGGCCACAGCAGTTCATCGTTGAGGCCAACACAA

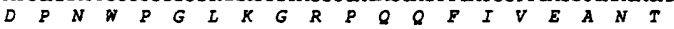
ATCCAAAGAACACTGCAGTTGCAATCTGTGGGCCTCCTAGAATGTATAAGTCAGTGTTTG AGGCCCTCATCAACTACGGTTATCGCCCAGAGAACATCTTCGTGACATTGGAGAGAGAA $\begin{array}{llllllllllllllllllll}E & A & L & I & N & Y & G & Y & R & P & E & N & I & F & V & T & L & E & R & R\end{array}$ TGAAATGTGGAATCGGGAAGTGCGGCCACTGCAACGTCGGAACGAGCACGAGCTGGAAGT $\begin{array}{lllllllllllllllllll}M & K & C & G & I & G & K & C & G & H & C & N & V & G & T & S & T & S & W\end{array}$ ACATCTGTAAAGATGGACCAGTCTTCACGTACTTCGACATAGTTTCAACCCCAGGACTGC $\begin{array}{llllllllllllllllllll}Y & I & C & K & D & G & P & V & F & T & Y & F & D & I & V & S & T & P & G & I\end{array}$ TGGACTGAGGTGAGGAAAATGGGAAAGTTAGGATTGGATTTTACGCATTAACCTCGTGC

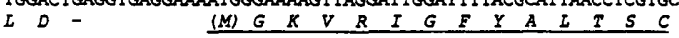
TACGGCTGTCAATTGCAGCTAGCTATGATGGACGAGTTATTACAACTTATCCCAAATGCT \begin{tabular}{llllllllllllllllllll}
$Y$ & $G$ & $C$ & $Q$ & $L$ & $Q$ & $L$ & $A$ & $M$ & $M$ & $D$ & $E$ & $L$ & $L$ & $Q$ & $L$ & $I$ & $P$ & $N$ & $A$ \\
\hline
\end{tabular}

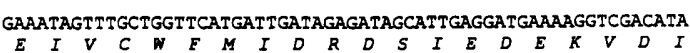
GCTTTTATAGAAGGAAGCGTTTCAACTGAGGAAGAAGTTGAACTCGTGAAAAAAATTAGG $\begin{array}{clllllllllllllllllll}A & E & I & E & G & S & V & S & T & E & E & E & V & E & V & K & K & I & R\end{array}$ GAGAATGCAAAGATCGTCGTTGCGGTTGGAGCTTGTGCTGTTCAAGGAGGAGTTCAGAGC $E$
$N$ TGGAGTGAAAAGCATTAGAAGAGCTCTGGAAGAAGGTTTATGGAGACGCAAAAGTCAAG $\begin{array}{llllllllllllllllllll}W & S & E & K & P & L & E & E & L & W & K & K & V & Y & G & D & A & K & V & K\end{array}$ ITCCAACCGAAGAAGGCTGAACCAGTTTCAAAATACATAAAAGTTGACTACAACATCTAC $\begin{array}{llllllllllllllllllllll}F & Q & P & K & K & A & E & P & V & S & K & Y & I & K & V & D & Y & N & I & Y\end{array}$ GGTTGCCCACCAGAGAAGAGGACTTCCTCTACGCCCTGGGAACATTCTTGATTGGTTCA $\begin{array}{llllllllllllllllllll}G & C & P & P & E & K & K & D & F & L & Y & A & L & G & T & F & L & I & G & S\end{array}$

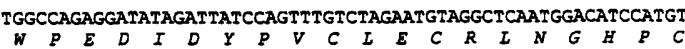
ATCCTTCTTGAGAAAGGAGAACCCTGTCTAGGTCCAGTAACAAGGGCAGGATGTAACGCG

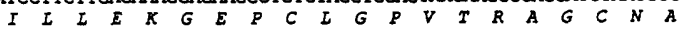

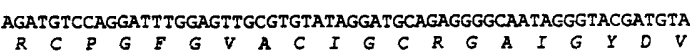

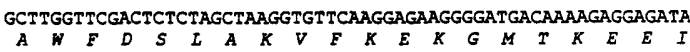
ATTGAGAGAATGAAAATGTTCAATGGACATGATGAGAGGGTTGAGAAAATGGTTGAAAAA $I \quad E \quad R \quad M \quad K \quad M \quad F \quad N \quad G \quad H \quad D \quad E \quad R \quad V \quad E \quad K \quad M \quad V \quad E \quad K$ ATATTCTCAGGTGGTGAACAATGAGAACCTCTATCTTCCAATCACCATTGATCATATAG $I E S G G E Q$

$$
\begin{array}{lllllllllllll}
M & K & N & L & Y & L & P & I & I & I & D & H & I
\end{array}
$$

CAAGAGTTGAGGGGAAGGGTGGTGTGGAGATAATAATTGGGGATGATGGAGTCAAGGAGG $\begin{array}{lllllllllllllllllllll}A & R & V & E & G & K & G & G & V & E & I & I & I & G & D & D & G & V & K & E\end{array}$ TCAAGCTAAACATAATTGAAGGGCCCAGATTCTTTGAGGCCATAACTATTGGGAGAAGC $\begin{array}{llllllllllllllllllll}V & K & L & N & I & I & E & G & P & R & F & F & E & A & I & T & I & G & K & K\end{array}$ TTGAGGAAGCTCTGGCCATTTACCCGAGAATATGCTCATTCTGTTCAGCCGCCCACAAGT $\begin{array}{llllllllllllllllllll}L & E & E & A & I & A & I & Y & P & R & I & C & S & F & C & S & A & A & H & K\end{array}$ TAACCGCATTAGAGGCTGCAGAAAAGGCCGTCGGTTTTGTCCCAAGGGAAGAGATACAGG $\begin{array}{llllllllllllllllllll}L & T & A & L & E & A & A & E & K & A & V & G & F & V & P & R & E & E & I & Q\end{array}$ CCCTTAGAGAaGTACTATACATCGgAGACATGATAGAGAGTCATGCCCTTCACCTATATC A $L$ R $E$ G

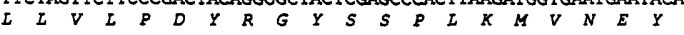
AGAGGGAGATAGAGATAGCCCTTAAGCTGAAGACCTTGGCACCTGGATGATGGACATTC $\begin{array}{lllllllllllllllllllllll}K & R & E & I & E & I & A & L & K & L & K & N & L & G & T & N & M & M & D & I\end{array}$ TAGGGTCAAGAGCCATACACCAAGAAAATGCGGTTTTGGGCGGATTCGGAAAGCTCCCTG $\begin{array}{lllllllllllllllllllll}L & G & S & R & A & I & H & Q & E & N & A & V & L & G & G & F & G & K & L & P\end{array}$ AGAAGAGTGTCCTTGAGAAATGAAAGCCGAGCTTAGGGAGCCCTACCACTTGCCGAGT ATACTTTTGAGTTATTTGCAAAGCTTGAGCAGTACAGCGAAGTTGAAGGGCCAATAACAC $\begin{array}{lllllllllllllllllllll}Y & T & F & E & L & F & A & K & L & E & Q & Y & S & E & V & E & G & P & I & T\end{array}$ ACTTGGCCGTGAAGCCGAGGGGAGATGCTTATGGAATTTATGGAGATTACATAAAGGCAA $\begin{array}{lllllllllllllllllllllllll}H & L & A & V & K & P & R & G & D & A & Y & G & I & Y & G & D & Y & I & K & A\end{array}$ GTGATGGGGAGGAGTTCCCAAGTGAAAAGTACAGAGATTATATAAAGGAGTTCGTCGTTG $\begin{array}{llllllllllllllllllll}S & D & G & E & E & F & P & S & E & K & Y & R & D & Y & I & K & E & F & V & V\end{array}$ AACACAGTTTTGCAAAC ACAGTCACTACAAGGGCAGACCCTTCATGGTTGGGGCTATAT

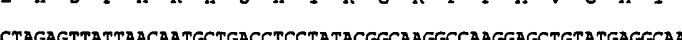

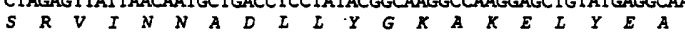
ACAAAGACCTATTGAAGGGACAAATCCGTTTGCAAATAACTTAGCCCAGGCCCTCGAAA $\begin{array}{llllllllllllllllllll}N & K & D & L & L & K & G & T & N & P & F & A & N & N & L & A & Q & A & L & E\end{array}$ TAGTTTACTTTATAGAGAGGGCAATAGATCTGCTCGACGAGGCTCTCGCCAAGTGGCCAA $\begin{array}{lllllllllllllllllllll}I & V & Y & F & I & E & R & A & I & D & L & L & D & E & A & L & A & K & N & P\end{array}$

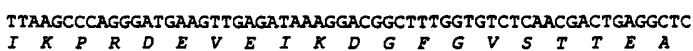
CAAGGGGATCTTAGTCTATGCCCTCAAAGTTGAGAATGGAAGGGTTTCTTATGCCGACA $\begin{array}{lllllllllllllllllllll}P & R & G & I & L & V & Y & A & L & K & V & E & N & G & R & V & S & Y & A & D\end{array}$ TAATAACACCTACAGCATTCAACTTGGCAATGATGGAAGAACATGTAAGAATGATGGCAG $\begin{array}{llllllllllllllllllllllllllll}I & I & T & P & T & A & E & N & L & A & M & M & E & E & H & V & R & M & M & A\end{array}$ AAAAGCACTACAATGACGATCCAGAAAGGTTAAAGATACTGGCTGAGATGGTTGTTAGGG $\begin{array}{llllllllllllllllllllll}E & K & H & Y & N & D & D & P & E & R & I & K & I & L & A & E & M & V & V & R\end{array}$ CTTATGATCCATGCATATCTTGCTCAGTCCACGTGGTIAGACTTTAATCCTTTTTATCTA TTTTTGTTGAGTACTTGTGGAGATTCTCATTCACATCACA

Fig. 2. For legend see facing page. 


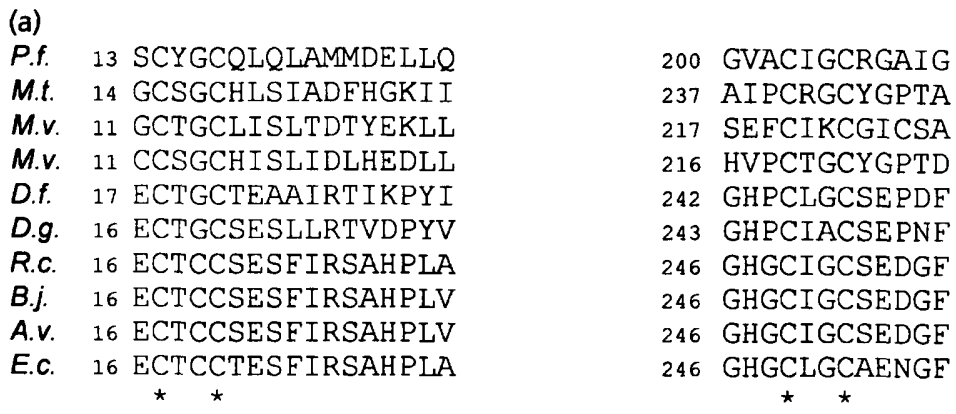

(b)

P.f. 43 RFFEAITIGKKLEEALAIYPRICSFCSAAHKLTALEAAEKAVGFVPREEIQA

M.t. 39 RGFEKFLQGRPIEEAPRIVPRICGICDVQHHLAAAKAVDACFGFEPEDVLPA

M.v. 41 RGEEKELVGKPAEFAPIAVSRFCGICPIAHATSAVEAIEDACGIVPPKDGLL

M.v. 22 RGEEKELEGRY IEDAPI FT PRICGICQVSHHLASAKAVDNVFGVKI PETANM

D.f. 50 RGLEI ILKGRDPRDAQHFTQRACGVCTYVHALASSRCVDDAVKVS I PANARM

D.g. 43 RGLEMILKGRDPRDAQHETQRACGVCTYVHALASVRAVDNCVGVKI PENATL

R.c. 53 RGLEVILKGRDPRDAWAFTERICGVCT'GTHALTSVRAVESALGITI PDNANS

B.j. 53 RGIEVILKNRDPRDAWAFTERICGVCT'GTHALTSVRAVENALGITI PENANS

A.v. 52 RGLEVILKGRDPRDAWAFVERICGVCTGTHALTSVRAVEDALDIRI PYNAHL

E.c. 54 RGLEIILQGRDPRDARAEVERICGVCTGVHALASVYAIEDAIGIKVPDNANI

409 EMVVRAYDPCISCSVH

433 EMVIRAYDPCLSCATH

377 EHVVRAYDPCVSCATQ

419 EMVIRAYDPCLSCATH

533 LRTVHAFDPCIACGVH

521 LRTVHSYDPCIACGVH

567 LRTLHSEDPCLACSTH

566 LRTIHSFDPCLACSTH

572 LRTLHSFDPCLACSTH

567 LRTLHSEDPCLACSTH

Fig. 3. Comparison of the conserved regions of the small (a) and the large (b) subunits of several [Ni-Fe] hydrogenases. (a) Regions comprising the putative $2 \mathrm{Fe}$ - or $4 \mathrm{Fe}$-type clusters at the $\mathrm{N}$ - and C-termini of the small subunits. (b) Regions comprising the nickel-coordination sites at the $\mathrm{N}$ - and $\mathrm{C}$-termini of the large subunits. P.f., P. furiosus; $M . t$., $M$. thermoautotrophicum (small and large subunits of the mvh operon); M.v., Methanococcus voltae (small and large subunits of the frc and vhc operons); D.f., Desulfovibrio fructosovorans; D.g., Desulfovibrio gigas; R.C., Rhodobacter capsulatus; B.j., Bradyrhizobium japonicum; A.v., Azotobacter vinelandii; E.c., E. coli (small and large subunit of the hydrogenase-1 operon). Identical residues are marked with asterisks. The numbers indicate the positions of each protein sequence within the corresponding subunit.

The genes corresponding to the $\alpha($ byd $A), \beta($ bydB), $\gamma$ $($ byd $G$ ) and $\delta($ bydD) subunits encode polypeptides of 428 , 367,292 and 260 amino acids, respectively. The calculated molecular masses of the subunits $(48700,41800,33200$ and $29600 \mathrm{Da}$, respectively) are in agreement with those estimated by SDS-PAGE analysis.

The bydG, bydD and byd $A$ genes begin with ATG codons, whereas bydB starts with the rare initiation codon GTG. GTG and TTG have already been found as initiator codons in other archaeal genes (Alex et al., 1990; Halboth \& Klein, 1992; Zwickl et al., 1990).

The comparison of the $\mathrm{N}$-terminal protein sequences with the corresponding deduced amino acid sequences indicates that none of the subunits are post-translationally processed at the amino-terminus, with the exception of the $\delta$ subunit, which lacks the initial methionine. There- fore the enzyme, in agreement with the experimental data, appears to be a cytoplasmic protein.

The bydBGD $A$ genes are closely linked: the stop and the start codons of the bydB/bydG genes and bydD/byd $A$ genes are overlapping, whereas byd $G$ and bydD are separated by 10 nucleotides. Each start codon is preceded by the typical ribosome-binding site found in most of the methanogen genes sequenced so far (Brown et al., 1989). Finally, two adjacent archaeal transcription termination signals (Brown et al., 1989) are located immediately downstream from the byd $A$ stop codon.

On the basis of the overall organization of the P. furiosus byd genes it appears that, like other multimeric hydrogenases (Przybyla et al., 1992; Reeve \& Beckler, 1990), the enzyme is encoded by a single transcription unit.

As far as the nucleotide composition is concerned, the

Fig. 2. Nucleotide sequence of the locus encoding the [Ni-Fe] hydrogenase of $P$. furiosus. The amino acid sequence of each open reading frame is given in one-letter code under the DNA sequence. Indicated are: the promoter region (box B), the putative ribosome-binding sites (asterisks), the start codons of the four subunits (short arrows), the transcription initiation site (vertical arrow next to box B) and the transcription termination signals (dotted lines). Amino acid residues determined by $\mathrm{N}$-terminal sequencing are underlined. The initiator methionine of hydD is in parentheses since it is absent in the protein sequence. 
$\mathrm{G}+\mathrm{C}$ content of the four structural genes $(44.3 \%)$ is higher than the average value calculated by Fiala \& Stetter (1986) for the total genome of $P$. furiosus $(37 \cdot 1 \%)$.

The most striking observation emerging from the analysis of the codon usage is the marked preference for AGG and AGA among the arginine codons. This is a feature in common with many other archaeal genes (Brown et al., 1989; Tiboni et al., 1993; Uemori et al., 1993; Zwickl et al., 1990).

Experimental data indicate that the structural elements of the constitutive archaeal promoters can be recognized in the T/CTTAT/AA ('box A') and in the ATGC ('box B') sequences. Box B, located 29-24 nucleotides downstream from box A, generally represents the site where transcription initiation takes place, GTP being the preferred initiator nucleotide. Box A appears to play the most important role in promoter recognition and transcription initiation, as shown by the sequence analysis of the archaeal promoters so far characterized (Hain et al., 1992) and by in vitro studies carried out with both total protein extracts and partially purified RNA polymerases (Hain $e t$ al., 1992; Hausner et al., 1991).

When the byd operon was scanned for promoter sequences, a box B motif was localized just upstream from bydB (underlined in Fig. 2). However, in the same region, the box A motif is absent if the AAATT'T sequence (centred 25 bases upstream from box B) and the TAA sequence (centred 32 bases upstream from box $B$ ) are not considered significant.

\section{Comparison of hydBGDA gene products}

1. hydD and hydA genes. The [Ni-Fe] hydrogenases have been classified on the basis of the number of subunits they are composed of. Although the presence of the gene for the large subunit is the sole feature common to all known nickel-containing enzymes, all the heterodimeric (two subunits) and many multimeric hydrogenases contain small subunits sharing a variable number of conserved cysteines, the function of which is to bind iron-sulfur clusters (for reviews see Przybyla et al., 1992; Reeve \& Beckler, 1990; Wu \& Mandrand, 1993).

Comparison of the bydBGD $A$ gene products with the [Ni-Fe] hydrogenases from different bacteria shows that the byd $D$ and byd $A$ products are clearly related to the small and large hydrogenase subunits, respectively (Figs 3 and 4).

The $P$. furiosus small subunit shows the highest degree of sequence identity with the Methanococcus voltae small subunits $(27 \cdot 6-36.4 \%)$ (Halboth \& Klein, 1992), the Methanobacterium thermoautotrophicum MvhG protein $(31.8 \%)$ (Reeve et al., 1989) and with two eubacterial sequences, the Acetomicrobium flavidum HydB (35.4\%) (G. M. Mura and others, unpublished) and Alcaligenes eutrophus HoxY proteins (29.5\%) (Tran-Betcke et al., 1990). Interestingly, the homology with the last two subunits is relatively high although the $\mathrm{C}$-termini of both HoxY and $A$. flavidum HydB appear to be truncated by approximately 50 amino acids. The homology with other small subunits from eubacterial origin is slightly less pronounced (22.2-27.2\% identity).

The small subunit of the $P$. furiosus hydrogenase contains 13 cysteines out of a total of 261 amino acids $(4.9 \%)$ : nine of them are located at conserved positions when compared to other hydrogenase small subunits and of these, four are arranged in the $\mathrm{C}-\mathrm{X}-\mathrm{X}-\mathrm{C}$ pattern at the $\mathrm{N}$ - and $\mathrm{C}$-termini (Fig. 3a).

The large subunits of both archaeal and eubacterial $[\mathrm{Ni}-\mathrm{Fe}]$ hydrogenases share several regions of wellconserved amino acid sequence with the $P$. furiosus $\alpha$ polypeptide ( $\mathrm{Hyd} A)$. In fact the overall sequence identity between HydA and the corresponding archaeal sequences ranges from $29 \cdot 2 \%$ to $34 \%$ whereas the identity with the eubacterial sequences goes from $27 \cdot 8 \%$ to $32 \%$. Within two of the most highly conserved regions, four cysteinyl residues participate in the $\mathrm{R}-\mathrm{X}-\mathrm{C}-\mathrm{X}-\mathrm{X}-\mathrm{C}-\mathrm{X}-\mathrm{X}-\mathrm{X}-\mathrm{H}$ motif at the N-terminus and in the D-P-C-X-X-C-X-X-H motif at the $\mathrm{C}$-terminus (Fig. 3b). This pattern, present in all the nickel-containing hydrogenases sequenced so far, was proposed to represent the nickel hexacoordination site of the enzyme. Indeed, Przybyla and coworkers have recently shown by site-directed mutagenesis that the arginine and the cysteine of the $\mathrm{N}$-terminal box and the aspartic acid, the proline and the cysteine of the $\mathrm{C}$ terminal box are required for the activity of the [Ni-Fe] hydrogenase-1 in E. coli (Przybyla et al., 1992).

As far as the relative position of the byd $A$ and bydD genes within the gene cluster is concerned, the gene encoding the hydrogenase small subunit $(b y d D)$ precedes the largesubunit-coding sequence (byd $A$ ). This organization is typical for all the [Ni-Fe] deazaflavine reducing hydrogenases sequenced so far and is conserved even in those cases where, in addition to the small and large subunits, other genes are found in the hydrogenase cluster (Fig. 4).

In conclusion, the $\alpha$ and $\delta$ subunits of the $P$. furiosus hydrogenase show the highest degree of homology with the large and the small subunits of hydrogenases from other archaea. Therefore the enzyme can be grouped with the class IV hydrogenases according to the recent classification by Wu \& Mandrand (1993). The similarity with the enzymes of class II, which includes the hydrogenases from Desulfovibrio species, is less pronounced, although the relative positions of the cysteine residues of the $P$. furiosus small subunit and the class II subunits appear to be generally conserved. Since it has recently been shown by crystallographic analysis that 10 of the cysteine residues of the Desulfovibrio gigas small subunit provide the coordination sites for one [3Fe-4S] cluster and two [4Fe-4S] clusters (one [4Fe-4S] cluster in the $\mathrm{N}$ terminal domain and the remaining clusters in the $\mathrm{C}$ terminal domain) (Volbeda et al., 1994), in the P. furiosus hydrogenase the mechanism of electron transfer for $\mathrm{H}_{2}$ production might be similar to that of the D. gigas enzyme.

On the other hand, the homology between HydD and HoxY of $A$. eutrophus appears to be relatively high (the $A$. eutrophus hydrogenase has also been included in class IV 
P. furiosus

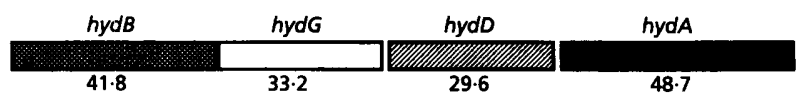

M. thermoautotrophicum

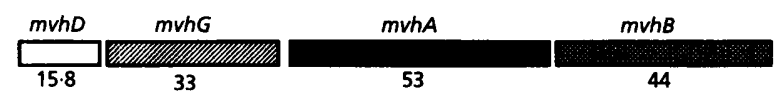

M. voltae (frc operon)

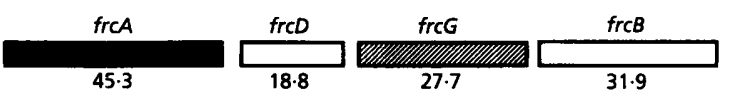

M. voltae (vhc operon)

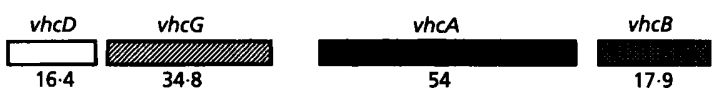

A. eutrophus

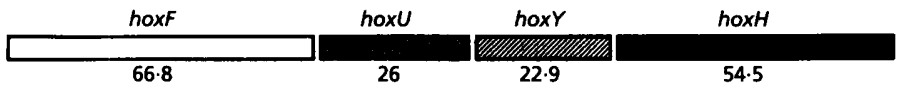

D. gigas

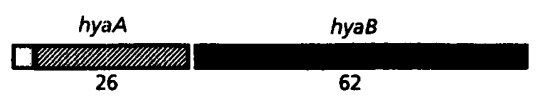

E. coli (hydrogenase-1)

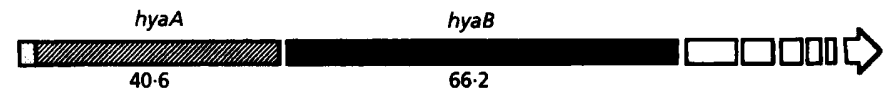

Homologous small subunit sequences

Homologous large subunit sequences

Ferredoxin-like sequences

Signal peptide sequences

Fig. 4. Schematic representation of the gene organization found in a few dimeric and multimeric [Ni-Fe] hydrogenase clusters.

by Wu \& Mandrand, 1993) but, since HoxY has a single [4Fe-4S] cluster (Przybyla et al., 1992) and lacks the Cterminal domain, the electron transfer system of the two enzymes might be different.

2. hydB and hydG genes. The homology search carried out with the bydB and bydG gene products identified a significant degree of sequence identity with the Asr $A$ and AsrB subunits of the $S$. typbimurium sulfite reductase $(31.7 \%$ and $34.6 \%$, respectively) (Huang \& Barrett, 1991) (Fig. 5).

Salmonella is unique among Enterobacteriaceae because it is endowed with two sulfite reductase systems. The first one, common to many Enterobacteriaceae and coded by the genes cysJ and cysI, is associated with the cysteine biosynthetic pathway and is responsible for the $\mathrm{H}_{2} \mathrm{~S}$ dependent conversion of 0 -acetylserine into cysteine. This sulfite reductase is a complex NADPH-dependent $\alpha_{8} \beta_{4}$ enzyme which contains FAD, [4Fe-4S] clusters and sirohaem to carry out the six-electron reduction of sulfite to sulfide without release of intermediates.

The second sulfite reductase system confers on Salmonella the unique ability to produce significant quantities of $\mathrm{H}_{2} \mathrm{~S}$ from sulfite under anaerobic conditions. From the recent work of Huang \& Barrett (1991) it has been shown that this sulfite reduction system can be ascribed to a metabolic pathway which is (i) independent from the cysteine biosynthetic pathway, (ii) activated under strict anaerobic conditions, (iii) linked to NADH rather than NADPH oxidation and (iv) regulated by available electron acceptors rather than by cysteine.

Three proteins are required for anaerobic $\mathrm{H}_{2} \mathrm{~S}$ evolution, the products of the genes asr $A, B$ and $C$. These proteins contain the structural elements which are necessary for sulfite reduction and are conserved in the sulfite reductase enzyme of the cysteine biosynthetic pathway. In particular, AsrA and AsrC harbour typical ferredoxin-like [4Fe-4S] clusters (C-X-X-C-X-X-C-X-X-X-C-P), AsrC carries the sirohaem-binding sequences and $A s r B$ contains two types of sequences that resemble the flavin-binding domains of a number of reductases (Huang \& Barrett, 1991) and regions found in many nucleotide-binding enzymes, respectively.

The similarities between AsrA and $\mathrm{HydB}$ and $\mathrm{AsrB}$ and HydG appear to be evenly distributed along the sequences apart from a relatively poor sequence homology between the $\mathrm{N}$-terminal regions of $\mathrm{AsrB}$ and $\mathrm{HydG}$. HydB appears to contain the ferredoxin-like cluster and $\mathrm{HydG}$ the nucleotide and the FAD-binding domains. This latter observation is particularly interesting in the light of very recent work (Smith et al., 1994) which demonstrates that NADPH rather than ferredoxin is the physiological electron carrier of the $P$. furiosus hydrogenase.

The similarities between $\mathrm{HydB}$ and Asr A and between HydG and AsrB are also particularly interesting considering that Ma et al. (1993) have recently demonstrated that the $P$. furiosus hydrogenase can catalyse polysulfide 
(a)

HYdB MRYVLPKXNTYEFL-BRI-KDWOKLYAP-VKI-SDKFYD-----FREIDDVRKIEFHYNRTIMPPKKFFFKPREKTFEFDISKPEYREV 81

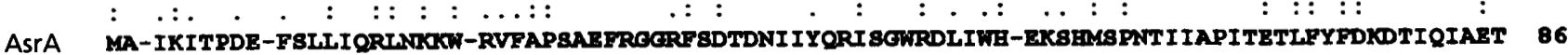

HydB IEEVEPFI IFGVHACDIYGIKIIDTVYL-DEFPDKY-YKVRREKGIIIGISGXPDEY--CFCNLRETDFADDGFDLF--FHELPDGLVR 165

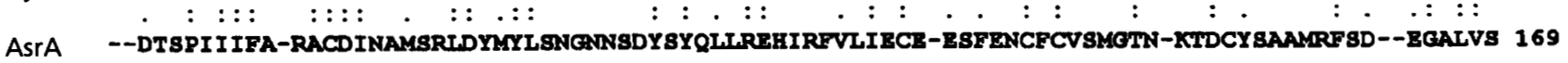

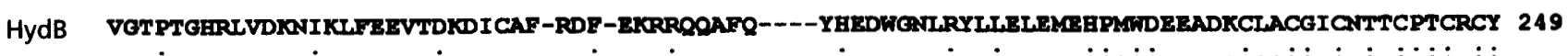

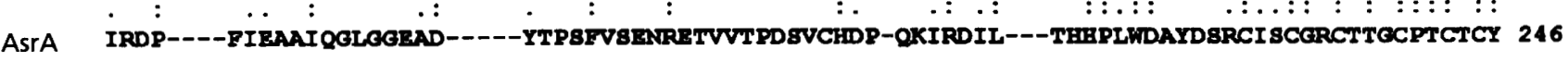

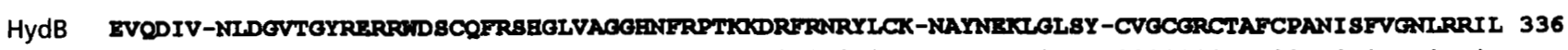

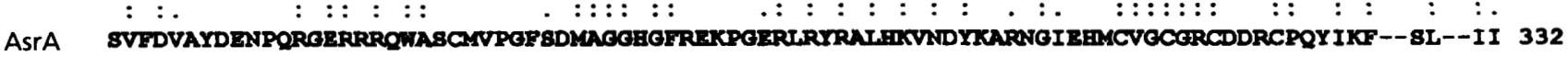

HYdB GLEENKCPPTVSEEIPKRGFAYBSNIRCDOV $\mathbf{3 6 7}$

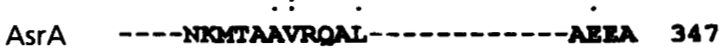

(b)

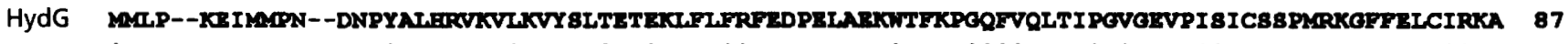

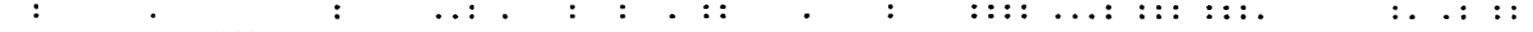

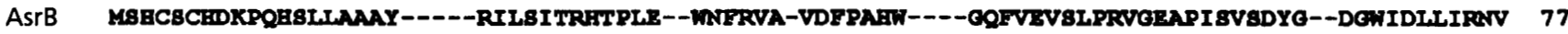

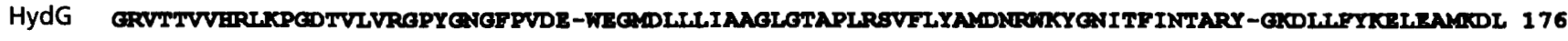

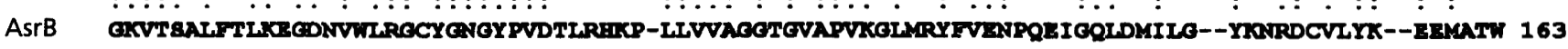

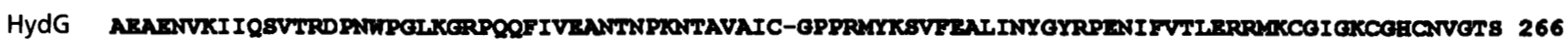

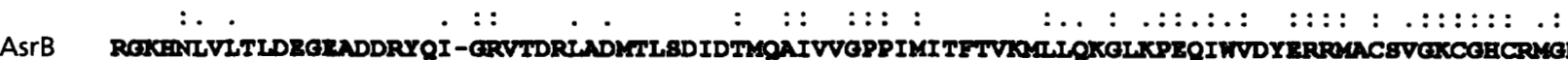

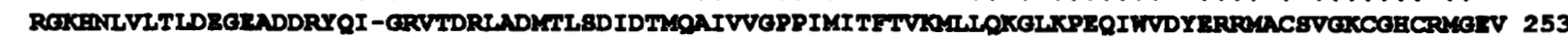

HydG TSWKYICWOPVTYYFIV8TPCITD 292

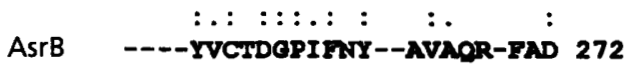

Fig. 5. Comparison of the $P$. furiosus hydB and the hydG gene products with the asr $A$ and asr $B$ gene products of the sulfite reductase enzyme from $S$. typhimurium. Single and double points represent amino acids similarity and identity, respectively. In (a), the highly conserved [4Fe-4S] ferredoxin-like sequences are underlined. In (b), the conserved cysteines within the C-X-X-C motif of the 2Fe- or 4Fe-type cluster are marked by asterisks and the sequences found in many nucleotide-binding enzymes are underlined.

reduction to $\mathrm{H}_{2} \mathrm{~S}$, allowing the disposal of excess reductant using either protons or polysulfides as electron acceptors.

Although the reduction reactions from sulfite to sulfide and from sulfur to sulfide are obviously chemically different, it is tempting to speculate on the existence of a common ancestor which divergently evolved to give two enzymes specialized in the reduction of sulfur at different oxidation states. The absence in the $P$. furiosus enzyme of sequences similar to AsrC, the subunit containing the sirohaem-binding domain which appears to be indispensable for sulfite reduction and conserved in both
Salmonella sulfite reductases, suggests a key role for AsrC in the six-electron reduction of sulfite to sulfide.

The homology studies of the $P$. furiosus hydrogenase described above suggest that the $\beta$ and $\gamma$ subunits might be involved in sulfur metabolism whereas the hydrogenase activity could be associated with the $\delta$ and $\alpha$ subunits. It would be interesting to test whether the $\mathrm{HydB}-\mathrm{HydG}$ and the $\mathrm{HydA}-\mathrm{HydD}$ dimers could be functionally dissociated from each other by testing the sulfur reductase activity of $\mathrm{HydB}-\mathrm{HydG}$ and the hydrogenase activity of HydA-HydD. The organization of the hydrogenases in complex enzyme structures endowed with more than one 
activity is not unusual. Typical examples are the foursubunit $A$. eutropbus hydrogenase in which the diaphorase activity can be separated from the hydrogenase activity (Tran-Betcke et al., 1990) and the $\mathrm{H}_{2}$ : heterodisulfide oxidoreductase complex of $M$. thermoautotrophicum in which the heterodisulfide-reductase activity can be separated from the $\mathrm{F}_{420}$-non-reducing hydrogenase (Setzke $e t$ al., 1994). Both genetic analysis such as heterologous gene expression and biochemical studies aimed at reconstituting the hydrogenase from its purified subunits might help in elucidating this interesting structural and functional aspect of the $P$. furiosus hydrogenase.

Ma et al. (1993) have shown that all the hydrogenases they tested show a significant sulfur reductase activity, regardless of the number of subunits they are composed of and besides the fact that none of the hydrogenases except the $P$. furiosus enzyme share homology to the asr genes.

This can be reconciled with our hypothesis that the structural elements required for sulfur reduction, which in the $P$. furiosus hydrogenase are embedded in the $\beta$ and/or $\gamma$ subunit(s), can either be localized on subunit(s) dispensable for the hydrogenase activity or inserted into the hydrogenase subunit(s). A careful analysis of many hydrogenase sequences suggests that the ferredoxin-like motifs, which are present on $\mathrm{HydB}$ and conserved in the sulfite reductase systems, might be involved in sulfur reduction. In fact they are also found in a large number of hydrogenases. For example, ferredoxin-like patterns are found in the large subunit of the Fe-only hydrogenase of Desulfovibrio vulgaris (Stokkermans et al., 1989; Voordouw \& Brenner, 1985), in the single-subunit Fe-only hydrogenase of Clostridium pasteurianum (Meyer \& Gagnon, 1991), in the HybA and $\mathrm{HycB}$ subunits of the multimeric [Ni-Fe] hydrogenases-2 and -3 of E. coli (Przybyla et al., 1992; Böhm et al., 1990), in the MvhB and FhrG subunits of the M. thermoautotrophicum hydrogenases (Reeve $e t$ al., 1989; Alex et al., 1990; Bokranz et al., 1988), in the VhcB subunit of Methanococcus voltae VHU hydrogenase (Halboth \& Klein, 1992) and in the HoxU subunit of the $A$. eutrophus NAD + hydrogenase (Tran-Betcke et al., 1990).

As already suggested by Ma et al. (1993), one could speculate on the presence, in the ancestor hydrogenase, of a high sulfur reductase activity to cope with and take advantage of the high-sulfur-containing environment. During the sulfhydrogenase evolution nature has taken the option of either maintaining the structural elements required for sulfur reduction on independent subunits (as it is the case for the $P$. furiosus hydrogenase) or concentrating them on the same subunit(s) used for the proton reduction $/ \mathrm{H}_{2}$ oxidation activity. The former situation should provide the enzyme with a more specialized sulfur reduction activity, the latter with a predominant hydrogenase activity.

\section{ACKNOWLEDGEMENTS}

We are deeply indebted to Dr M. W. W. Adams and Dr A. Kletzin for their helpful discussion and criticism to the manuscript. The critical reading of the paper by Dr F. de Ferra is also acknowledged. Finally we would like to thank $\mathrm{Dr}$ $\mathrm{P}$. Polverino for her support to the $\mathrm{N}$-terminal sequencing of the hydrogenase subunits and E. Iennaco for expert secretarial assistance. This work was performed under the management of the Research Institute of Innovative Technology for the Earth (RITE) as a part of the Research \& Development Project on Environmentally Friendly Technology for the Production of Hydrogen supported by the New Energy and Industrial Technology Development Organization (NEDO), Japan.

\section{REFERENCES}

Adams, M. W. W. \& Mortenson, L. E. (1984). The purification of hydrogenase II (uptake hydrogenase) from the anaerobic $\mathrm{N}_{2}$-fixing bacterium Clostridium pasteurianum. Biochim Biophys Acta 766, 51-61.

Alex, L. A., Reeve, J. N., Orme-Johnson, W. H. \& Walsh, C. T. (1990). Cloning, sequence determination and expression of the genes encoding the subunits of the nickel-containing 8-hydroxy-5deazaflavin reducing hydrogenase from Methanobacterium thermoautotropbicum $\Delta H$. Biocbemistry 29, 7237-7244.

Bøhm, R., Sauter, M. \& Bock, A. (1990). Nucleotide sequence and expression of an operon in Escherichia coli coding for formate hydrogenlyase components. Mol Microbiol 4, 231-243.

Bokranz, M., Bäumner, G., Allmansberger, R., Ankel-Fuchs, D. \& Klein, A. (1988). Cloning and characterization of the methyl coenzyme $\mathrm{M}$ reductase genes from Methanobacterium thermoautotrophicum. J Bacteriol 170, 568-577.

Bradford, M. M. (1976). A rapid and sensitive method for the quantitation of microgram quantities of protein utilizing the principle of protein-dye binding. Anal Biochem 72, 248-254.

Brown, J. W., Daniels, C. J. \& Reeve, J. N. (1989). Gene structure, organization and expression in archaebacteria. CRC Crit Rev Microbiol 16, 287-338.

Bryant, F. O. \& Adams, M. W. W. (1989). Characterization of hydrogenase from the hyperthermophilic archaebacterium Pyrococcus furiosus. J Biol Chem 264, 5070-5079.

Dower, W. J., Miller, J. F. \& Ragsdale, C. W. (1988). High efficiency transformation of E. coli by high voltage electroporation. Nucleic Acids Res 16, 6127-6145.

Fiala, G. \& Stetter, K. O. (1986). Pyrococcus furiosus sp. nov. represents a novel genus of marine heterotrophic archaebacteria growing optimally at $100^{\circ} \mathrm{C}$. Arch Microbiol 145, 56-61.

Hain, J., Reiter, W.-D., Hudephol, U. \& Zillig, W. (1992). Elements of an archaeal promoter defined by mutational analysis. Nucleic Acids Res 20, 5423-5428.

Halboth, S. \& Klein, A. (1992). Methanococcus voltae harbors four gene clusters potentially encoding two $[\mathrm{Ni}-\mathrm{Fe}]$ and two $[\mathrm{NiFeSe}]$ hydrogenases, each of the cofactor $\mathrm{F}_{420}$-reducing or $\mathrm{F}_{420}$-nonreducing types. Mol \& Gen Genet 233, 217-224.

Hausner, W., Frey, G. \& Thomm, M. (1991). Control regions of an archaeal gene. A TATA box and an initiator element promote cellfree transcription of the $\mathrm{RNA}^{\mathrm{val}}$ gene of Methanococcus vannielii. $J$ Mol Biol 222, 495-508.

Huang, C. J. \& Barrett, E. L. (1991). Sequence analysis and expression of the Salmonella typhimurium asr operon encoding production of hydrogen sulfide from sulfite. $J$ Bacteriol 173, 1544-1553.

Huber, R., Kristjansson, J. K. \& Stetter, K. O. (1987). Pyrobaculum gen. nov., a new genus of neutrophilic, rod-shaped archaebacteria from continental solfataras growing optimally at $100^{\circ} \mathrm{C}$. $\mathrm{Arch}$ Microbiol 149, 95-101.

Laemmli, U. K. (1970). Cleavage of structural proteins during the assembly of the head of bacteriophage T4. Nature 227, 680-685. 
LeGendre, N. \& Matsudaira, P. (1989). Gel electrophoresis. In $A$ Practical Guide to Protein and Peptide Purification for Microsequencing, pp. 52-69. Edited by P. Matsudaira. San Diego: Academic Press.

Ma, K., Schicho, R. N., Kelly, R. M. \& Adams, M. W. W. (1993). Hydrogenase of the hyperthermophile Pyrococcus furiosus is an elemental sulfur reductase or sulfhydrogenase: evidence for a sulfur-reducing hydrogenase ancestor. Proc Natl Acad Sci US A 90, 5341-5344.

Matsudaira, P. (1987). Sequence from picomole quantities of proteins electroblotted onto polyvinylidene difluoride membranes. J Biol Chem 262, 10035-10038.

Meyer, J. \& Gagnon, J. (1991). Primary structure of hydrogenase I from Clostridium pasteurianum. Biochemistry 30, 9697-9704.

Mura, G. M., Pedroni, P., Branduzzi, P., Grandi, G., Park, J.-B., Adams, M. W. W. \& Galli, G. (1991). Characterization of Pyrococcus furiosus hydrogenase. Proceedings of the 15th International Congress of Biochemistry, Jerusalem, p. 313.

Ochman, H., Medhora, M. M., Garza, D. \& Hartl, D. L. (1990). Amplification of flanking sequences by inverse PCR. In PCR Protocols: a Guide to Methods and Applications, pp. 219-227. Edited by M. A. Innis, D. H. Gelfand, J. J. Sninsky \& T. J. White. San Diego: Academic Press.

Przybyla, A. E., Robbins, J., Menon, N. \& Peck, H. D., Jr (1992). Structure-function relationship among the nickel-containing hydrogenases. FEMS Microbiol Rev 88, 109-136.

Reeve, J. N. \& Beckler, G. S. (1990). Conservation of primary structure in prokaryotic hydrogenases. FEMS Microbiol Rev 87, 419-424.

Reeve, J. N., Beckler, G. S., Cram, D. S., Hamilton, P. T., Brown, J.W., Krzycki, J. A., Kolodziej, A. F., Alex, L., Orme-Johnson, W. H. \& Walsh, C. T. (1989). A hydrogenase-linked gene in Methanobacterium thermoautotrophicum strain $\Delta \mathrm{H}$ encodes a polyferredoxin. Proc Natl Acad Sci US A 86, 3031-3035.

Sambrook, J., Fritsch, E. F. \& Maniatis, T. (1989). Molecular Cloning: a Laboratory Manual, 2nd edn. Cold Spring Harbor, NY: Cold Spring Harbor Laboratory.

Sanger, F., Nicklen, S. \& Coulson, A. R. (1977). DNA sequencing with chain-terminating inhibitors. Proc Natl Acad Sci USA 74, 5463-5467.

Schicho, R. N., Ma, K., Adams, M. W. W. \& Kelly, R. M. (1993). Bioenergetics of sulfur reduction in the hyperthermophilic archaeon Pyrococcus furiosus. J Bacteriol 175, 1823-1830.

Schuler, G. D., Altschul, S. F. \& Lipman, D. J. (1991). A workbench for multiple alignment construction and analysis. Proteins 9, 180-190.

Setzke, E., Hedderich, R., Heiden, S. \& Thauer, R. K. (1994). $\mathrm{H}_{2}$ : heterodisulfide oxidoreductase complex from Methanobacterium thermoautotrophicum. Composition and properties. Eur $J$ Biochem 220, 139-148.
Smith, E. T., Blamey, J. M., Hutchins, A., Ramakrishnan, V., Zhou, Z.-H. \& Adams, M. W. W. (1994). Structure and function of novel hydrogenases from microorganisms growing near and above $100{ }^{\circ} \mathrm{C}$. Proceedings of the Fourth International Conference on the Molecular Biology of Hydrogenases, Noordwijkerhout, The Netherlands, pp. 3-4.

Stetter, K. O. (1986). Diversity of extremely thermophilic archaebacteria. In Thermophiles: General, Molecular and Applied Microbiology, pp. 39-74. Edited by T. D. Brock. New York: John Wiley \& Sons.

Stetter, K. O., König, H. \& Stackebrandt, E. (1983). Pyrodictium gen. nov., a new genus of submarine disc-shaped sulphur reducing archaebacteria growing optimally at $105^{\circ} \mathrm{C}$. Syst Appl Microbiol 4, 535-551.

Stokkermans, J., van Dongen, W., Kaan, A., van den Berg, W. \& Veeger, C. (1989). byd $\gamma$, a gene from Desulfovibrio vulgaris (Hildenborough) encodes a polypeptide homologous to the periplasmic hydrogenase. FEMS Microbiol Lett 58, 217-222.

Tiboni, O., Cammarano, P. \& Sanangelatoni, A. M. (1993). Cloning and sequencing of the gene encoding glutamine synthetase I from the archaeum Pyrococcus woesei: anomalous phylogenies inferred from analysis of archaeal and bacterial glutamine synthetase I sequences. J Bacteriol 175, 2961-2969.

Tran-Betcke, A., Warnecke, U., Bocker, C., Zaborosch, C. \& Friedrich, B. (1990). Cloning and nucleotide sequences of the genes for the subunits of NAD-reducing hydrogenase of Alcaligenes eutrophus H16. J Bacteriol 172, 2920-2929.

Uemori, T., Ishino, Y., Toh, H., Asada, K. \& Kato, I. (1993). Organization and nucleotide sequence of the DNA polymerase gene from the archaeon Pyrococcus furiosus. Nucleic Acids Res 21, 259-265.

Volbeda, A., Piras, C., Charon, M. H., Hatchikian, E. C., Frey, M. \& Fontecilla-Camps, J. C. (1994). X-ray structure determination of the nickel containing hydrogenase from Desulfovibrio gigas. Proceedings of the Fourth International Conference on the Molecular Biology of Hydrogenases, Noordwijkerhout, The Netherlands, pp. 146-147.

Voordouw, G. \& Brenner, S. (1985). Nucleotide sequence of the gene encoding the hydrogenase from Desulfovibrio vulgaris (Hildenborough). Eur J Biochem 148, 515-520.

Wu, L.-F. \& Mandrand, M. A. (1993). Microbial hydrogenases: primary structure, classification, signatures and phylogeny. FEMS Microbiol Rev 104, 243-270.

Zwickl, P., Fabry, S., Bogedain, C., Haas, A. \& Hensel, R. (1990). Glyceraldehyde-3-phosphate dehydrogenase from the hyperthermophilic archaebacterium Pyrococcus woesei: characterization of the enzyme, cloning and sequencing of the gene, and expression in Escherichia coli. J Bacteriol 172, 4329-4338.

Received 9 August 1994; revised 6 October 1994; accepted 13 October 1994. 